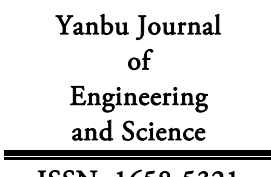

ISSN: $1658-5321$
Vol. 1, October $2010(1431 \mathrm{H})$

www.yic.edu.sa/yjes

\title{
ARTIFICIAL NEURAL NETWORK APPROACH: AN APPLICATION TO HARMONIC LOAD FLOW FOR RADIAL SYSTEMS
}

\author{
A.Arunagiri ${ }^{1}$, Suresh $\mathrm{K}^{2}$, B.Venkatesh ${ }^{3}$, R.Ramesh Kumar ${ }^{1}$ and Mustajab Ahmed Khan ${ }^{1}$ \\ ${ }^{1}$ EEET Department, Yanbu Industrial College, Yanbu, KSA. \\ ${ }^{2}$ Research Scholar, Bharath University, Chennai, India. \\ ${ }^{3}$ Faculty of Engineering, Ryerson University, Toronto, Canada. \\ Contact: aarunagiri@yic.edu.sa.
}

\begin{abstract}
Radial Distribution Systems (RDS) require special load flow methods to solve power flow equations owing to their high $\mathrm{R} / \mathrm{X}$ ratio. Increasing use of power electronic devices and effect of magnetic saturation cause harmonics in RDS. This paper reports a multilayer feed forward ANN with error back propagation learning algorithm for the calculation of bus voltages and power loss for different harmonic components. The proposed method is tested upon a 33-bus RDS and the results are reported for various harmonics. Extensive testing of the proposed ANN based approach indicates its viability for harmonic load flow assessment for radial systems.
\end{abstract}

KEYwORDS: Radial Distribution Systems; Harmonic components.

\section{INTRODUCTION}

Analysis of distribution system using power flow is important in the field of power systems. Distribution systems are predominantly characterized by their high $\mathrm{R} / \mathrm{X}$ ratio and radial topology. Matrix based iterative methods do not lend themselves for radial distribution systems owing to these characteristics. Numerous algorithms have been developed using simple recursive equations [1-3].

Rapid industrialization has led to increasing use of power electronic devices in transmission and distribution systems. Modern industrial and domestic consumers use an ever-increasing number of devices that primarily employ power electronics based power-conditioners. Use of AC machines employing magnetic circuits in the saturation region also introduces harmonics in electrical power systems.
Many existing methods for distribution system load flow, fail to obtain a solution in several instances. Large RDS have complicated structure and are subject to changes in their topology frequently for maintenance, load balancing, network reconfiguration and emergency operations under the umbrella of Supervisory Control and Data Acquisition (SCADA). SCADA requires a fast Distribution Load Flow (DLF) algorithm that computes the voltage solution very rapidly for online scheduling.

Load flow calculation in harmonic polluted radial system with distributed generation has been carried out using abstract data types with complex parameters[4].

A multiple-frequency three-phase load-flow with two sub models including the fundamental power flow (FPF) and harmonic frequency power-flow (HPF) model has been developed and the standard Fourier analysis 
was used to deal with the harmonic loads to get injection currents [5]. Fuzzy number based methodology for harmonic load-flow calculation including uncertainities has been applied for interconnected system[6].

Artificial neural network approach has been applied for the radial distribution system analysis [7].From the above, one may see the need for an efficient algorithm that reliably and rapidly solves the power flow equations for radial distribution systems characterized by high $\mathrm{R} / \mathrm{X}$ ratio, radial topology and for various harmonic loads.

In this paper an ANN based harmonic load flow solution technique for the radial system has been developed. A database consisting of different load patterns and the corresponding voltage solution with the power loss is created for third, fifth and seventh order of harmonics using ladder iterative technique. The neural network is trained to learn the features of the load to estimate the bus voltage, angle and the total loss. The trained neural network can be instantly recalled to give output for an untrained set of inputs without going through the conventional iterative procedure, and that saves considerable execution time especially on a large systems.

The proposed method makes use of multilayer feed forward ANN with error back propagation learning algorithm for the calculation of bus voltages and power loss for different harmonic components.

In section 2, a simple ladder network technique is explained for solving the radial system power balance equations. Using this technique, a data base providing information of the possible real and reactive power demands for various harmonics at different buses and their corresponding voltage solution is created. Section 3 briefly introduces the Back Propagation Network, its architecture, training algorithm and recognition phase. Section 4 discusses an implementation of BPN for determining the bus voltages for various harmonics. Section 5 presents the results of sample systems being studied by the proposed method for different harmonics. Section 6 presents the conclusion.

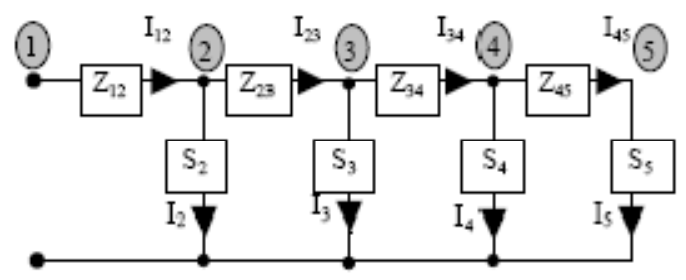

Fig. 1. Ladder Network

\section{LADDER ITERATIVE TECHNIQUE}

It is assumed that the ladder network parameters for lines, loads and substation voltage $V_{S}$ are known. The voltage solution of this network can be obtained by repeating the forward and backward sweeps iteratively.

\subsection{FORWARD SWEEP:}

Compute bus voltages and associated currents starting from last bus to the first bus.

$$
\left.\begin{array}{l}
I_{i}=\left(S_{i} / V_{i}\right)^{*} \\
I_{i-1, i}=I_{i}+I_{i, i+1} \\
V_{i}=V_{i+1}+Z_{i, i+1} * I_{i-1, i}
\end{array}\right\} \text { for } \mathrm{i}=4,3,2,1 .
$$

For $\mathrm{i}=5, \mathrm{~V}_{5}$ is assumed to be $\mathrm{V}_{\mathrm{S}}$ in the first iteration and equals the value computed in the backward sweep in the subsequent iterations. $I_{5}$ is computed using (1).

\subsection{BACKWARD SWEEP:}

The backward sweep starts from $2^{\text {nd }}$ bus to the last bus ( $5^{\text {th }}$ bus). Taking $\mathrm{V}_{1}=\mathrm{V}_{\mathrm{S}}$. The $\mathrm{i}^{\text {th }}$ bus voltages are computed as below using current values computed in the forward sweep:

$V_{i}=V_{i-1}+Z_{i-1, i} * I_{i-1, i} \quad$ for $i=2,3,4,5$.

The forward and backward sweeps are continued until the difference between the specified voltage at source and computed voltage in the forward sweep is within the tolerance limit. 


\section{BPN ARCHITECTURE}

The most common BPN architecture is presented in Fig. 2. It is shown to have three layers, namely, input, hidden and output layers. Other applications may have several hidden layers. During training, several sets of input and their corresponding output vectors are considered. The training phase is used to determine the weights between the input, hidden and output layers.

The neurons used in the study use the sigmoid activation function defined by the following equation:

$\left[\begin{array}{l}\text { Neuron } \\ \text { output }\end{array}\right]=\frac{1.0}{1.0+\mathrm{e}^{-\alpha \mathrm{v}}}$

where $\alpha$ is the abruptness of the sigmoid function and the $\mathrm{v}$ is the total input to the neuron.

Let the vector $\mathrm{X}$ represent an input to the input layer as shown in the Fig. 2. The net input at the hidden layers is computed by the matrix equation as below:

$\mathrm{V}_{\mathrm{H}}=[\mathrm{WH}] \mathrm{X}$

where $\mathrm{WH}_{\mathrm{ji}}$ denotes the weight between $i^{\text {th }}$ input layer node and $j^{\text {th }}$ hidden layer node.

The output of the hidden layer nodes are given by

$\mathrm{Y}_{\mathrm{H}}=\Phi\left(\mathrm{V}_{\mathrm{H}}\right)$

where $\Phi$ is the appropriate activation function. In a similar manner, the total input at the output layer is given by the following equation:

$\mathrm{V}_{\mathrm{O}}=[\mathrm{WO}] \mathrm{V}_{\mathrm{H}}$

The output of the output layer node is given by

$\mathrm{Y}=\boldsymbol{\Phi}\left(\mathrm{V}_{\mathrm{O}}\right)$

The steps for well-established training algorithm based upon Newton's steepest descent technique is given below:

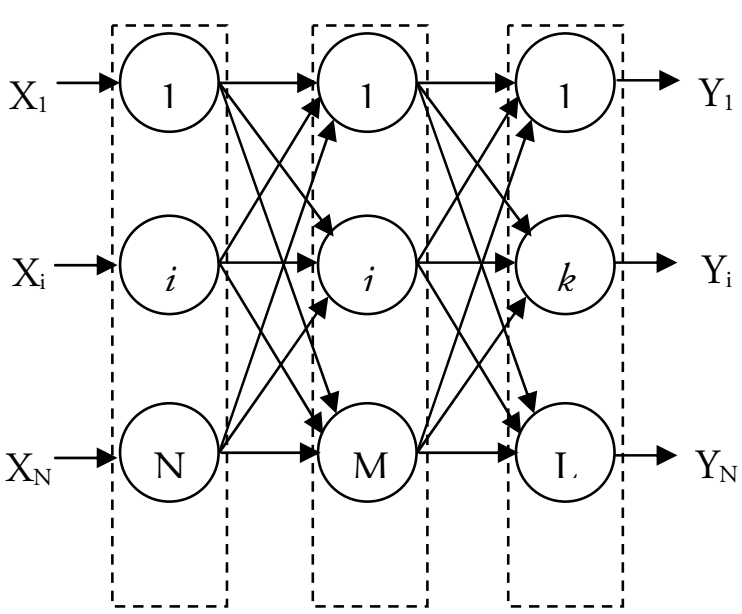

Fig. 2. Basic BPN Architecture

1. Read the training set and randomly initialize the weights. Set iteration index $n=1$.

2. Set training set index $p=1$.

3. $\quad$ Propagate $\mathrm{X}^{\mathrm{p}}$ through the network.

4. Determine the error vector of the $p^{\text {th }}$ training set

$\mathrm{E}^{\mathrm{P}}=\mathrm{O}^{\mathrm{P}}-\mathrm{Y}^{\mathrm{p}}$ where $\mathrm{O}^{\mathrm{P}}$ is the vector of expected output.

5. Correct the weights using Newton's steepest descent technique.

6. If $p<$ number training sets $P$, set $p=$ $p+1$ and go to step 3 .

7. If $\sum_{\mathrm{p}=1}^{\mathrm{P}}\left|\mathrm{E}^{\mathrm{p}}\right|^{2}>$ tolerance $\varepsilon$, increment the iteration index $n$ and go to step 2 .

The above method works well and has been well documented. The method requires that, the input and output to be from a continuous domain. Further, it also requires that the input and output set of vectors are noncontradictory for a successful training and operational function.

The RDS under study consists of 33 buses. The substation transformer is connected to bus 1 and there is no direct loading at bus 1 . The voltage at bus 1 is known and is specified as 1.0 per unit. The resistance and reactance of lines between any two buses and the base load condition is mentioned in table 1 . 


\section{IMPLEMENTATION OF BPN TO DETERMINE HARMONIC LOAD FLOW SOLUTION}

The input vector for the BPN is the real and reactive power loads for different harmonics at various buses of the power system. The resistance of the different lines remains the same for different harmonics where as the reactance changes according to the order of harmonics. Load flow solution for different load patterns is obtained using ladder iterative technique with the relevant impedance component for the third, fifth and seventh order harmonics.

Sixty sets of loads were created by the following scheme:

(a) Varying both the real and reactive power loads simultaneously at all the load buses of the radial system.

(b) Varying both the real and reactive power loads simultaneously at a single load bus of the radial system.

(c) Varying only the real power load at a single load bus of the radial system.

(d) Varying only the reactive power load at a single load bus of the radial system.

Equation (8) and (9) represents the train input and train target matrix for a particular order of harmonics.

$\begin{array}{rll}\mathrm{P}_{1,1} & \mathrm{P}_{2,1} & \mathrm{P}_{60,1} \\ \mathrm{P}_{1,2} & \mathrm{P}_{2,2} & \mathrm{P}_{60,2} \\ \mathrm{P}_{1,3} & \mathrm{P}_{2,3} & \mathrm{P}_{60,3} \\ \cdot & \cdot & \cdot \\ \cdot & \cdot & \cdot \\ \mathrm{P}_{1,32} & \mathrm{P}_{2,32} & \mathrm{P}_{60,32} \\ \mathrm{Q}_{1,1} & \mathrm{Q}_{2,1} & \mathrm{Q}_{60,1} \\ \mathrm{Q}_{1,2} & \mathrm{Q}_{2,2} & \mathrm{Q}_{60,2} \\ \mathrm{Q}_{1,3} & \mathrm{Q}_{2,3} & \mathrm{Q}_{60,3} \\ \cdot & \cdot & \cdot \\ \cdot & \cdot & \cdot \\ \mathrm{Q}_{1,32} & \mathrm{Q}_{2,32} & \mathrm{Q}_{60,32}\end{array}$

Where $P_{i, j}$ and $Q_{i, j}$ represents the real and reactive power demands at the $\mathrm{j}^{\text {th }}$ bus of the $\mathrm{i}^{\text {th }}$ load pattern for the particular order of harmonics.

$\begin{array}{ccc}\mathrm{V}_{1,1} & \mathrm{~V}_{2,1} & \mathrm{~V}_{60,1} \\ \mathrm{~V}_{1,2} & \mathrm{~V}_{2,2} & \mathrm{~V}_{60,2} \\ \mathrm{~V}_{1,3} & \mathrm{~V}_{2,3} & \mathrm{~V}_{60,3} \\ \cdot & \cdot & \cdot \\ \cdot \cdot & \cdot & \cdot \\ \cdot \cdot & \cdot & \cdot \\ \mathrm{V}_{1,32} & \mathrm{~V}_{2,32} & \mathrm{~V}_{60,32} \\ \delta_{1,1} & \delta_{2,1} & \delta_{60,1} \\ \delta_{1,2} & \delta_{2,2} & \delta_{60,2} \\ \delta_{1,3} & \delta_{2,3} & \delta_{60,3} \\ \cdot & \cdot & \cdot \\ \cdot & \cdot & \cdot \\ \cdot & \cdot & \cdot \\ \delta_{1,32} & \delta_{2,32} & \delta_{60,32} \\ \mathrm{PL}_{1} & \mathrm{PL}_{2} & \mathrm{PL} 60\end{array}$

(9)

Where $V_{i, j}$ and $\delta_{i, j}$ represents the voltage and corresponding angle solution at the $\mathrm{j}^{\text {th }}$ bus of the $\mathrm{i}^{\text {th }}$ load pattern for the particular order of harmonics. $\mathrm{PL}_{\mathrm{i}}$ represents the total loss for the $\mathrm{i}^{\text {th }}$ load pattern for the particular order of harmonics calculated from the ladder iterative technique.

For the multi layer feed forward ANN, tansigmoid transfer function (TANSIG) is used as activation function. For the considered 33 bus system, 64 input layer nodes $\quad(32+32$, for real and reactive powers at each bus, there is no direct load connected at bus 1 ) and 65 output layer nodes are used. $(32+32+1$, for voltage magnitude and angle at each bus. The voltage magnitude and angle is specified at the substation, the last node represents the power loss for the particular load condition).

After successful training of the ANN it should able to produce the bus voltage magnitude with angle and the total power loss for any of 
the untrained input load pattern with minimum time and maximum accuracy.

\section{RESULTS AND DISCUSSION}

A 33 bus radial distribution system Fig. 3 was tested using the proposed method. The power flow equations were solved using the ladder iterative technique explained in section 2.In order to achieve a broad representation of the power system in the Back Propagation Network, approximately sixty input-output vector pairs were generated for each of the harmonics for the considered 33-bus system. The BPN was trained in MATLAB $^{\oplus}$ environment and the trained result for third harmonics is shown in Fig. 4. Thereafter, the $\mathrm{BPN}$ is ready for use. The results from the conventional harmonic load flow solution and from the trained ANN for different harmonics are shown in Table 2. The method seems to work well and is found to be very efficient and fast. The execution time to reach the voltage solution from the trained ANN is approximately one third of the execution time of the conventional method. The bus voltages and the power loss from BPN for the test inputs for the different order of harmonics are compared with ladder iterative technique solution and is listed in table 2 .

For the minor changes in the network from the far end of the source, will not affect the results very much. However if the system topology changed from the sending end side, the proposed approach will not work satisfactorily, since the considered system is radial. Effectiveness of the proposed method for the system topology changes can be considered for the future work.

As long as if the ANN is trained with the sufficient data (it may be real or simulated) the outcome of the ANN will be the expected outcome.

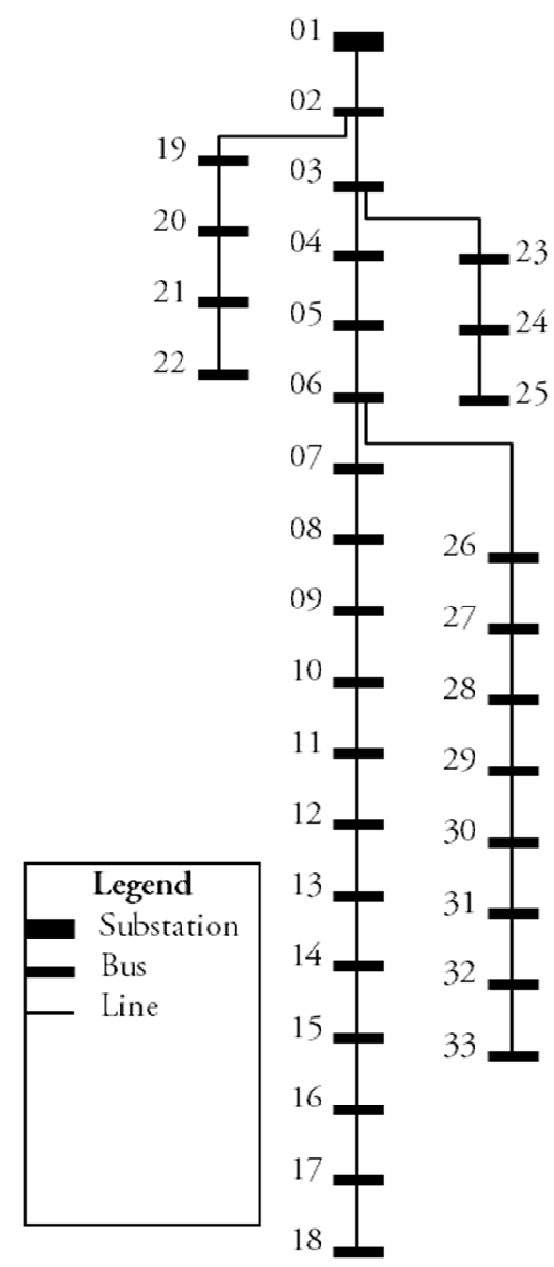

Fig.3. 33-bus radial distribution system

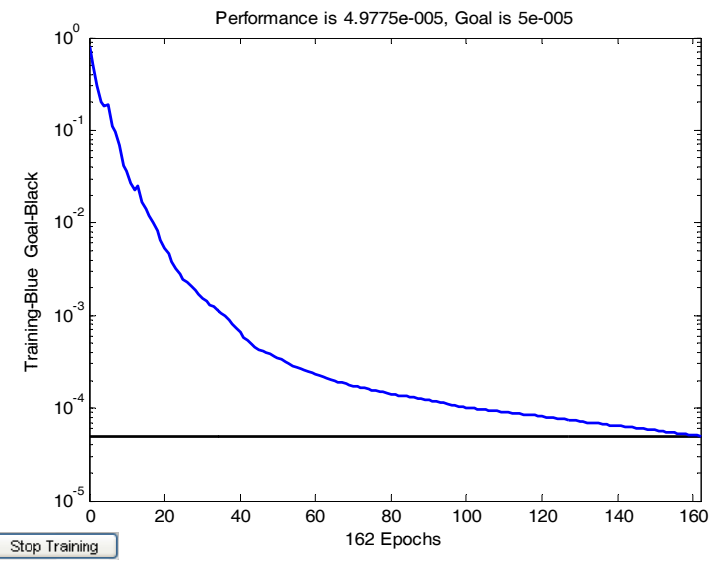

Fig.4. BPN Training Results for third harmonics

\section{CONCLUSIONS}

This paper presents a well defined approach to determine the harmonic load flow solution of a radial distribution system for various order of harmonics. Since collecting data from 
the real system with harmonic sources for a large system is a difficult task, a 33 bus radial system is considered for analysis. Several load sets were considered and their solution was assessed using the conventional method of ladder network technique. Then using these sets of input and output vector pairs, the Back Propagation Network is trained. Thereafter, the $\mathrm{BPN}$ is ready for use wherein, given a harmonic load, it gives out the voltage solution with minimum time and maximum accuracy.

\section{REFERENCES}

[1] Kersting, W. H., and Mendive, D. L., 1976, "An application of ladder network theory to the solution of three phase radial load flow problem", IEEE PES winter meeting, New Work, January.

[2] Kersting, W. H., 1984, "A method to design and operation of distribution system", IEEE Transactions on PAS-103, pp. 1945-1952.

[3] Stevens, R. A., Rizy, D. T. and Puruker, S. L., 1986, "Performance of conventional power flow routines for real time distribution automation applications", Proceedings of $18^{\mathrm{Th}}$ southeastern symposium on systems theory, (IEEE computer society), pp. 196-200.

[4] Ciprian Bud, Bogdan Tomoiaga, Mercia Chindris."The Load Flow Calculation in Harmonic Polluted Radial Electric Networks with Distributed Generation" $9^{\text {th }}$ International conference on Electrical power quality and Utilisation, Barcelona, 9-11 Oct 2007.

[5] Whei-Min Lin, Tung-Sheng Zhan, Ming-Tong Tsay," Multiple-frequency three-phase load flow for harmonic analysis" IEEE transactions on Power Systems, Vol 19 Issue 2, PP 897-904, May 2004.

[6] A. A. Romero, H .C. Zini, G. Ratta and R. Dib," A fuzzy number based methodology for harmonic load-flow calculation, considering uncertainties" Lat. Am. appl. res. vol.38 no.3 Bahía Blanca July/Sept. 2008

[7] A.Arunagiri,B.Venkatesh, K.Ramasamy, "Artificial neural network approach-an application to radial loadflow algorithm", IEICE
Electronics Express, Vol. 3, No. 14, pp.353-360, 2006

[8] W. F. Tinny and C. E. Hart, Power flow solution of the Newton Method, IEEE Transactions PAS, Vol. PAS-86, No.11, Nov. 1967.

[9] B. Stott and O. Alsac, "Fast Decoupled Load Flow" IEEE Transactions on Power Apparatus and Systems, Vol.PAS-93,pp.859-869, May/June 1974.

[10] B. Stott, ' Review of Load Flow Calculation Methods', Proceedings of the IEEE, Vol. 62, No. 7, July 1984 
Yanbu Journal of Engineering and Science Vol. 1 (2010)

TABLE 1: SYSTEM UNDER STUDY

\begin{tabular}{|c|c|c|c|c|c|c|c|}
\hline \multirow[b]{2}{*}{$\begin{array}{l}\dot{0} \\
\dot{z} \\
\dot{s}\end{array}$} & \multirow[b]{2}{*}{ 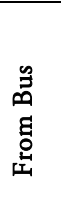 } & \multirow[b]{2}{*}{ 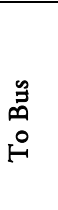 } & \multirow[b]{2}{*}{$\underset{\widetilde{a}}{\overparen{c}}$} & \multicolumn{4}{|c|}{ Fundamental } \\
\hline & & & & $\underset{x}{\widehat{C}}$ & $\underset{a}{\stackrel{3}{y}}$ & 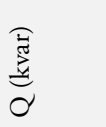 & $\begin{array}{l}\stackrel{\overrightarrow{\dot{H}}}{\grave{\Xi}} \\
>\end{array}$ \\
\hline 1 & 1 & 2 & 0.0922 & 0.047 & 100 & 60 & 1 \\
\hline 2 & 2 & 3 & 0.493 & 0.2511 & 90 & 40 & 0.997 \\
\hline 3 & 3 & 4 & 0.366 & 0.1864 & 120 & 80 & 0.9829 \\
\hline 4 & 4 & 5 & 0.3811 & 0.1941 & 60 & 30 & 0.9754 \\
\hline 5 & 5 & 6 & 0.819 & 0.707 & 60 & 20 & 0.9679 \\
\hline 6 & 6 & 7 & 0.1872 & 0.6188 & 200 & 100 & 0.9495 \\
\hline 7 & 7 & 8 & 1.7114 & 1.2351 & 200 & 100 & 0.946 \\
\hline 8 & 8 & 9 & 1.03 & 0.74 & 60 & 20 & 0.9323 \\
\hline 9 & 9 & 10 & 1.044 & 0.74 & 60 & 20 & 0.926 \\
\hline 10 & 10 & 11 & 0.1966 & 0.065 & 45 & 30 & 0.9201 \\
\hline 11 & 11 & 12 & 0.3744 & 0.1238 & 60 & 35 & 0.9192 \\
\hline 12 & 12 & 13 & 1.468 & 1.155 & 60 & 35 & 0.9177 \\
\hline 13 & 13 & 14 & 0.5416 & 0.7129 & 120 & 80 & 0.9115 \\
\hline 14 & 14 & 15 & 0.591 & 0.526 & 60 & 10 & 0.9092 \\
\hline 15 & 15 & 16 & 0.7463 & 0.545 & 60 & 20 & 0.9078 \\
\hline 16 & 16 & 17 & 1.289 & 1.721 & 60 & 20 & 0.9064 \\
\hline 17 & 17 & 18 & 0.732 & 0.574 & 90 & 40 & 0.9043 \\
\hline 18 & 2 & 19 & 0.164 & 0.1565 & 90 & 40 & 0.9037 \\
\hline 19 & 19 & 20 & 1.5042 & 1.3554 & 90 & 40 & 0.9965 \\
\hline 20 & 20 & 21 & 0.4095 & 0.4784 & 90 & 40 & 0.9929 \\
\hline 21 & 21 & 22 & 0.7089 & 0.9373 & 90 & 40 & 0.9922 \\
\hline 22 & 3 & 23 & 0.4512 & 0.3083 & 90 & 50 & 0.9916 \\
\hline 23 & 23 & 24 & 0.898 & 0.7091 & 420 & 200 & 0.9793 \\
\hline 24 & 24 & 25 & 0.896 & 0.7011 & 420 & 200 & 0.9726 \\
\hline 25 & 6 & 26 & 0.203 & 0.1034 & 60 & 25 & 0.9693 \\
\hline 26 & 26 & 27 & 0.2842 & 0.1447 & 60 & 25 & 0.9475 \\
\hline 27 & 27 & 28 & 1.059 & 0.9337 & 60 & 20 & 0.945 \\
\hline 28 & 28 & 29 & 0.8042 & 0.7006 & 120 & 70 & 0.9335 \\
\hline 29 & 29 & 30 & 0.5075 & 0.2585 & 200 & 600 & 0.9253 \\
\hline 30 & 30 & 31 & 0.9744 & 0.963 & 150 & 70 & 0.9217 \\
\hline 31 & 31 & 32 & 0.3105 & 0.3619 & 210 & 100 & 0.9176 \\
\hline 32 & 32 & 33 & 0.341 & 0.5302 & 60 & 40 & 0.9167 \\
\hline & & & & & Losse & $.9983 \mathrm{~kW}$ & \\
\hline
\end{tabular}


Yanbu Journal of Engineering and Science Vol. 1 (2010)

TABLE 2A

3rd Harmonic, load $=1 \%$ of total load, voltage magnitude: $0.1 \mathrm{pu}$

\begin{tabular}{|c|c|c|c|c|c|c|c|c|c|}
\hline \multicolumn{5}{|c|}{ System Parameters } & \multicolumn{3}{|c|}{ Load } & \multirow[b]{2}{*}{$\begin{array}{c}\text { Voltage } \\
\text { Solution from } \\
\text { BPN in pu }\end{array}$} & \multirow[b]{2}{*}{$\begin{array}{l}\text { Percentage } \\
\text { Accuracy }\end{array}$} \\
\hline $\begin{array}{c}\text { Line } \\
\text { number }\end{array}$ & $\begin{array}{c}\text { Sending } \\
\text { Bus }\end{array}$ & $\begin{array}{l}\text { Receiving } \\
\text { Bus }\end{array}$ & $\begin{array}{c}\text { Resistance } \\
\Omega\end{array}$ & $\begin{array}{c}\text { Reactance } \\
\Omega\end{array}$ & $\begin{array}{c}\text { Real } \\
\text { Power } \\
\text { KW }\end{array}$ & $\begin{array}{l}\text { Reactive } \\
\text { Power } \\
\text { KVAr }\end{array}$ & $\begin{array}{c}\text { Voltage } \\
\text { Solution in pu } \\
\text { (conventional) }\end{array}$ & & \\
\hline 1 & 1 & 2 & 0.0922 & 0.141 & 1 & 0.6 & 0.1000 & 0.1000 & 100 \\
\hline 2 & 2 & 3 & 0.493 & 0.7533 & 0.9 & 0.4 & 0.0995 & 0.0997 & 99.98 \\
\hline 3 & 3 & 4 & 0.366 & 0.5592 & 1.2 & 0.8 & 0.0972 & 0.0975 & 99.97 \\
\hline 4 & 4 & 5 & 0.3811 & 0.5823 & 0.6 & 0.3 & 0.0960 & 0.0958 & 99.98 \\
\hline 5 & 5 & 6 & 0.819 & 2.121 & 0.6 & 0.2 & 0.0947 & 0.0950 & 99.97 \\
\hline 6 & 6 & 7 & 0.1872 & 1.8564 & 2 & 1 & 0.0911 & 0.0914 & 99.97 \\
\hline 7 & 7 & 8 & 1.7114 & 3.7053 & 2 & 1 & 0.0901 & 0.0901 & 100 \\
\hline 8 & 8 & 9 & 1.03 & 2.22 & 0.6 & 0.2 & 0.0877 & 0.0874 & 99.97 \\
\hline 9 & 9 & 10 & 1.044 & 2.22 & 0.6 & 0.2 & 0.0866 & 0.0870 & 99.96 \\
\hline 10 & 10 & 11 & 0.1966 & 0.195 & 0.45 & 0.3 & 0.0856 & 0.0850 & 99.94 \\
\hline 11 & 11 & 12 & 0.3744 & 0.3714 & 0.6 & 0.35 & 0.0855 & 0.0849 & 99.94 \\
\hline 12 & 12 & 13 & 1.468 & 3.465 & 0.6 & 0.35 & 0.0852 & 0.0852 & 100 \\
\hline 13 & 13 & 14 & 0.5416 & 2.1387 & 1.2 & 0.8 & 0.0841 & 0.0837 & 99.96 \\
\hline 14 & 14 & 15 & 0.591 & 1.578 & 0.6 & 0.1 & 0.0836 & 0.0832 & 99.96 \\
\hline 15 & 15 & 16 & 0.7463 & 1.635 & 0.6 & 0.2 & 0.0834 & 0.0830 & 99.96 \\
\hline 16 & 16 & 17 & 1.289 & 5.163 & 0.6 & 0.2 & 0.0831 & 0.0835 & 99.96 \\
\hline 17 & 17 & 18 & 0.732 & 1.722 & 0.9 & 0.4 & 0.0827 & 0.0837 & 99.9 \\
\hline 18 & 2 & 19 & 0.164 & 0.4695 & 0.9 & 0.4 & 0.0826 & 0.0822 & 99.96 \\
\hline 19 & 19 & 20 & 1.5042 & 4.0662 & 0.9 & 0.4 & 0.0994 & 0.0994 & 100 \\
\hline 20 & 20 & 21 & 0.4095 & 1.4352 & 0.9 & 0.4 & 0.0989 & 0.0994 & 99.95 \\
\hline 21 & 21 & 22 & 0.7089 & 2.8119 & 0.9 & 0.4 & 0.0988 & 0.0972 & 99.84 \\
\hline 22 & 3 & 23 & 0.4512 & 0.9249 & 0.9 & 0.5 & 0.0986 & 0.0976 & 99.9 \\
\hline 23 & 23 & 24 & 0.898 & 2.1273 & 4.2 & 2 & 0.0967 & 0.0980 & 99.87 \\
\hline 24 & 24 & 25 & 0.896 & 2.1033 & 4.2 & 2 & 0.0956 & 0.0956 & 100 \\
\hline 25 & 6 & 26 & 0.203 & 0.3102 & 0.6 & 0.25 & 0.0951 & 0.0954 & 99.97 \\
\hline 26 & 26 & 27 & 0.2842 & 0.4341 & 0.6 & 0.25 & 0.0907 & 0.0927 & 99.8 \\
\hline 27 & 27 & 28 & 1.059 & 2.8011 & 0.6 & 0.2 & 0.0902 & 0.0912 & 99.9 \\
\hline 28 & 28 & 29 & 0.8042 & 2.1018 & 1.2 & 0.7 & 0.0877 & 0.0707 & 98.3 \\
\hline 29 & 29 & 30 & 0.5075 & 0.7755 & 2 & 6 & 0.0859 & 0.0879 & 99.8 \\
\hline 30 & 30 & 31 & 0.9744 & 2.889 & 1.5 & 0.7 & 0.0852 & 0.0832 & 99.8 \\
\hline 31 & 31 & 32 & 0.3105 & 1.0857 & 2.1 & 1 & 0.0844 & 0.0834 & 99.9 \\
\hline \multirow[t]{2}{*}{32} & 32 & 33 & 0.341 & 1.5906 & 0.6 & 0.4 & 0.0842 & 0.0812 & 99.7 \\
\hline & & & & Total Loss & $2.3947 \mathrm{KW}$ & $\begin{array}{l}\text { Loss } \\
\text { from } \\
\mathrm{BPN}\end{array}$ & $2.52 \mathrm{KW}$ & & $88.47 \%$ \\
\hline
\end{tabular}


Yanbu Journal of Engineering and Science Vol. 1 (2010)

TABLE 2B

5th Harmonic, load $=0.5 \%$ of total load, voltage magnitude: $0.075 \mathrm{pu}$

\begin{tabular}{|c|c|c|c|c|c|c|c|c|c|}
\hline \multicolumn{5}{|c|}{ System Parameters } & \multicolumn{3}{|c|}{ Load } & \multirow[b]{2}{*}{$\begin{array}{c}\text { Voltage } \\
\text { Solution } \\
\text { from BPN in } \\
\mathrm{pu}\end{array}$} & \multirow[b]{2}{*}{$\begin{array}{c}\text { Percentage } \\
\text { Accuracy }\end{array}$} \\
\hline $\begin{array}{c}\text { Line } \\
\text { number }\end{array}$ & $\begin{array}{l}\text { Sending } \\
\text { Bus }\end{array}$ & $\begin{array}{c}\text { Receiving } \\
\text { Bus }\end{array}$ & $\begin{array}{c}\text { Resistance } \\
\Omega\end{array}$ & $\begin{array}{c}\text { Reactance } \\
\Omega\end{array}$ & $\begin{array}{l}\text { Real } \\
\text { Power } \\
\text { KW }\end{array}$ & $\begin{array}{l}\text { Reactive } \\
\text { Power } \\
\text { KVAr }\end{array}$ & $\begin{array}{c}\text { Voltage } \\
\text { Solution in pu } \\
\text { (conventional) }\end{array}$ & & \\
\hline 1 & 1 & 2 & 0.0922 & 0.235 & 0.5 & 0.3 & 0.0750 & 0.0750 & 100 \\
\hline 2 & 2 & 3 & 0.493 & 1.2555 & 0.45 & 0.2 & 0.0745 & 0.0723 & 99.78 \\
\hline 3 & 3 & 4 & 0.366 & 0.932 & 0.6 & 0.4 & 0.0723 & 0.0743 & 99.8 \\
\hline 4 & 4 & 5 & 0.3811 & 0.9705 & 0.3 & 0.15 & 0.0711 & 0.0722 & 99.89 \\
\hline 5 & 5 & 6 & 0.819 & 3.535 & 0.3 & 0.1 & 0.0698 & 0.0596 & 98.98 \\
\hline 6 & 6 & 7 & 0.1872 & 3.094 & 1 & 0.5 & 0.0658 & 0.0648 & 99.9 \\
\hline 7 & 7 & 8 & 1.7114 & 6.1755 & 1 & 0.5 & 0.0646 & 0.0743 & 99.03 \\
\hline 8 & 8 & 9 & 1.03 & 3.7 & 0.3 & 0.1 & 0.0621 & 0.0635 & 99.86 \\
\hline 9 & 9 & 10 & 1.044 & 3.7 & 0.3 & 0.1 & 0.0609 & 0.0629 & 99.8 \\
\hline 10 & 10 & 11 & 0.1966 & 0.325 & 0.225 & 0.15 & 0.0598 & 0.0548 & 99.5 \\
\hline 11 & 11 & 12 & 0.3744 & 0.619 & 0.3 & 0.175 & 0.0597 & 0.0596 & 99.99 \\
\hline 12 & 12 & 13 & 1.468 & 5.775 & 0.3 & 0.175 & 0.0595 & 0.0595 & 100 \\
\hline 13 & 13 & 14 & 0.5416 & 3.5645 & 0.6 & 0.4 & 0.0583 & 0.0575 & 99.92 \\
\hline 14 & 14 & 15 & 0.591 & 2.63 & 0.3 & 0.05 & 0.0577 & 0.0583 & 99.94 \\
\hline 15 & 15 & 16 & 0.7463 & 2.725 & 0.3 & 0.1 & 0.0574 & 0.0563 & 99.89 \\
\hline 16 & 16 & 17 & 1.289 & 8.605 & 0.3 & 0.1 & 0.0572 & 0.0532 & 99.6 \\
\hline 17 & 17 & 18 & 0.732 & 2.87 & 0.45 & 0.2 & 0.0567 & 0.0565 & 99.98 \\
\hline 18 & 2 & 19 & 0.164 & 0.7825 & 0.45 & 0.2 & 0.0565 & 0.0546 & 99.81 \\
\hline 19 & 19 & 20 & 1.5042 & 6.777 & 0.45 & 0.2 & 0.0745 & 0.0775 & 99.7 \\
\hline 20 & 20 & 21 & 0.4095 & 2.392 & 0.45 & 0.2 & 0.0739 & 0.0735 & 99.96 \\
\hline 21 & 21 & 22 & 0.7089 & 4.6865 & 0.45 & 0.2 & 0.0738 & 0.0733 & 99.95 \\
\hline 22 & 3 & 23 & 0.4512 & 1.5415 & 0.45 & 0.25 & 0.0737 & 0.0735 & 99.98 \\
\hline 23 & 23 & 24 & 0.898 & 3.5455 & 2.1 & 1 & 0.0718 & 0.0735 & 99.83 \\
\hline 24 & 24 & 25 & 0.896 & 3.5055 & 2.1 & 1 & 0.0708 & 0.0608 & 99 \\
\hline 25 & 6 & 26 & 0.203 & 0.517 & 0.3 & 0.125 & 0.0703 & 0.0623 & 99.2 \\
\hline 26 & 26 & 27 & 0.2842 & 0.7235 & 0.3 & 0.125 & 0.0654 & 0.0654 & 100 \\
\hline 27 & 27 & 28 & 1.059 & 4.6685 & 0.3 & 0.1 & 0.0649 & 0.0669 & 99.8 \\
\hline 28 & 28 & 29 & 0.8042 & 3.503 & 0.6 & 0.35 & 0.0621 & 0.0631 & 99.9 \\
\hline 29 & 29 & 30 & 0.5075 & 1.2925 & 1 & 3 & 0.0601 & 0.0631 & 99.7 \\
\hline 30 & 30 & 31 & 0.9744 & 4.815 & 0.75 & 0.35 & 0.0593 & 0.0583 & 99.9 \\
\hline 31 & 31 & 32 & 0.3105 & 1.8095 & 1.05 & 0.5 & 0.0585 & 0.0485 & 99 \\
\hline 32 & 32 & 33 & 0.341 & 2.651 & 0.3 & 0.2 & 0.0582 & 0.0602 & 99.8 \\
\hline & & & & Total Loss & $1.189 \mathrm{KW}$ & $\begin{array}{c}\text { Loss from } \\
\text { BPN }\end{array}$ & $1.03 \mathrm{KW}$ & & 84.1 \\
\hline
\end{tabular}


TABLE 2C

7 th Harmonic, load $=0.25 \%$ of total load, voltage magnitude: $0.0 .05 \mathrm{pu}$

\begin{tabular}{|c|c|c|c|c|c|c|c|c|c|}
\hline \multicolumn{5}{|c|}{ System Parameters } & \multicolumn{3}{|c|}{ Load } & \multirow[b]{2}{*}{$\begin{array}{c}\text { Voltage } \\
\text { Solution from } \\
\text { BPN in pu }\end{array}$} & \multirow[b]{2}{*}{$\begin{array}{c}\text { Percentage } \\
\text { Accuracy }\end{array}$} \\
\hline $\begin{array}{c}\text { Line } \\
\text { number }\end{array}$ & $\begin{array}{l}\text { Sending } \\
\text { Bus }\end{array}$ & $\begin{array}{l}\text { Receiving } \\
\text { Bus }\end{array}$ & $\begin{array}{c}\text { Resistance } \\
\Omega\end{array}$ & $\begin{array}{c}\text { Reactance } \\
\Omega\end{array}$ & $\begin{array}{l}\text { Real } \\
\text { Power } \\
\text { KW }\end{array}$ & $\begin{array}{c}\text { Reactive } \\
\text { Power } \\
\text { KVAr }\end{array}$ & $\begin{array}{c}\text { Voltage } \\
\text { Solution in pu } \\
\text { (conventional) }\end{array}$ & & \\
\hline 1 & 1 & 2 & 0.0922 & 0.329 & 0.25 & 0.15 & 0.0500 & 0.0490 & 99.9 \\
\hline 3 & 3 & 4 & 0.366 & 1.3048 & 0.3 & 0.2 & 0.0467 & 0.0456 & 99.89 \\
\hline 4 & 4 & 5 & 0.3811 & 1.3587 & 0.15 & 0.075 & 0.0450 & 0.0450 & 100 \\
\hline 5 & 5 & 6 & 0.819 & 4.949 & 0.15 & 0.05 & 0.0433 & 0.0422 & 99.89 \\
\hline 6 & 6 & 7 & 0.1872 & 4.3316 & 0.5 & 0.25 & 0.0376 & 0.0386 & 99.9 \\
\hline 7 & 7 & 8 & 1.7114 & 8.6457 & 0.5 & 0.25 & 0.0356 & 0.0346 & 99.9 \\
\hline 9 & 9 & 10 & 1.044 & 5.18 & 0.15 & 0.05 & 0.0302 & 0.0313 & 99.89 \\
\hline 10 & 10 & 11 & 0.1966 & 0.455 & 0.1125 & 0.075 & 0.0286 & 0.0276 & 99.9 \\
\hline 11 & 11 & 12 & 0.3744 & 0.8666 & 0.15 & 0.0875 & 0.0285 & 0.0265 & 99.8 \\
\hline 12 & 12 & 13 & 1.468 & 8.085 & 0.15 & 0.0875 & 0.0282 & 0.0262 & 99.8 \\
\hline 13 & 13 & 14 & 0.5416 & 4.9903 & 0.3 & 0.2 & 0.0263 & 0.0250 & 99.87 \\
\hline 14 & 14 & 15 & 0.591 & 3.682 & 0.15 & 0.025 & 0.0254 & 0.0244 & 99.9 \\
\hline 15 & 15 & 16 & 0.7463 & 3.815 & 0.15 & 0.05 & 0.0249 & 0.0238 & 99.89 \\
\hline 16 & 16 & 17 & 1.289 & 12.047 & 0.15 & 0.05 & 0.0245 & 0.0255 & 99.9 \\
\hline 17 & 17 & 18 & 0.732 & 4.018 & 0.225 & 0.1 & 0.0236 & 0.0236 & 100 \\
\hline 18 & 2 & 19 & 0.164 & 1.0955 & 0.225 & 0.1 & 0.0234 & 0.0238 & 99.96 \\
\hline 20 & 20 & 21 & 0.4095 & 3.3488 & 0.225 & 0.1 & 0.0488 & 0.0468 & 99.8 \\
\hline 21 & 21 & 22 & 0.7089 & 6.5611 & 0.225 & 0.1 & 0.0487 & 0.0477 & 99.9 \\
\hline 22 & 3 & 23 & 0.4512 & 2.1581 & 0.225 & 0.125 & 0.0486 & 0.0486 & 100 \\
\hline 23 & 23 & 24 & 0.898 & 4.9637 & 1.05 & 0.5 & 0.0461 & 0.0451 & 99.9 \\
\hline 24 & 24 & 25 & 0.896 & 4.9077 & 1.05 & 0.5 & 0.0451 & 0.0442 & 99.91 \\
\hline 25 & 6 & 26 & 0.203 & 0.7238 & 0.15 & 0.0625 & 0.0445 & 0.0345 & 99 \\
\hline 26 & 26 & 27 & 0.2842 & 1.0129 & 0.15 & 0.0625 & 0.0371 & 0.0377 & 99.94 \\
\hline 27 & 27 & 28 & 1.059 & 6.5359 & 0.15 & 0.05 & 0.0365 & 0.0368 & 99.97 \\
\hline 28 & 28 & 29 & 0.8042 & 4.9042 & 0.3 & 0.175 & 0.0325 & 0.0321 & 99.96 \\
\hline 29 & 29 & 30 & 0.5075 & 1.8095 & 0.5 & 1.5 & 0.0297 & 0.0295 & 99.98 \\
\hline 30 & 30 & 31 & 0.9744 & 6.741 & 0.375 & 0.175 & 0.0287 & 0.0289 & 99.98 \\
\hline 31 & 31 & 32 & 0.3105 & 2.5333 & 0.525 & 0.25 & 0.0273 & 0.0270 & 99.97 \\
\hline \multirow[t]{2}{*}{32} & 32 & 33 & 0.341 & 3.7114 & 0.15 & 0.1 & 0.0270 & 0.0258 & 99.88 \\
\hline & & & & Total Loss & $0.9358 \mathrm{KW}$ & $\begin{array}{l}\text { Loss } \\
\text { from } \\
\text { BPN }\end{array}$ & $0.84 \mathrm{KW}$ & & 90.42 \\
\hline
\end{tabular}




\section{تطبيق أسلوب شبكات العصب الصناعي على سريان الاحمال في الانظمة المحورية في ظل توافقيات غير مرغوب فيها}

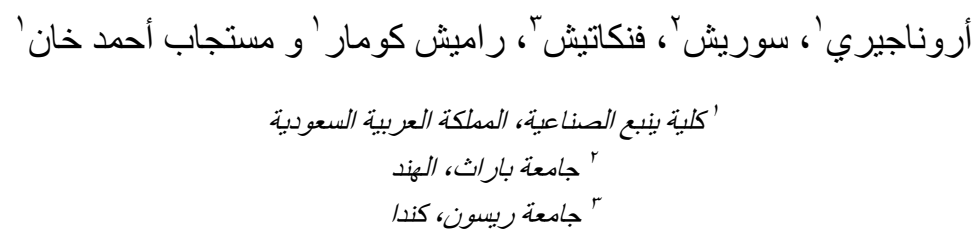

الملخص:

تتطلب الانظمة المحورية لتوزيع الطاقة طرق خاصة لسريان الاحمال لكي يحل معادلات سريان القوي. نبزيادة استعمال الاجهزة الالكترونية وتأثنير التشبع المغناطيسي أدي الى ظهور توافقيات غير مرغوب فيها في انظمة التوزيع المحورية. تقدم هذه المقالة البحثية نظام متعدد الطبقات للتغذية الامامية مع وجود برنامج لسريان الاخطاء في الاتجاه المعاكس وذللك لحساب الجهد وفقد القوة لاكثر من مركبة تو افقية غير مرغوب فيها. تم اختبار الطرقة المقترحة على بس مسار للتوزيع المحوري وتم تبويب النتائج طبقا لكل تردد من التو اققيات غير المرغوب فيها. وقد اثبتت هذه الاختبار ات للطريقة المقترحة جدوي هذه الطريقة لتقييم سريان الاحمال في الانظمة الحورية في وجود تو افقيات غير مرغوب فيها. 